\title{
Etmopteridae bioluminescence: dorsal pattern specificity and aposematic use
}

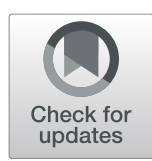

Laurent Duchatelet ${ }^{1 *}$ (D), Nicolas Pinte ${ }^{1}$, Taketeru Tomita ${ }^{2,3}$, Keiichi Sato $^{2}$ and Jérôme Mallefet ${ }^{1}$

\begin{abstract}
Background: In the darkness of the ocean, an impressive number of taxa have evolved the capability to emit light. Many mesopelagic organisms emit a dim ventral glow that matches with the residual environmental light in order to camouflage themselves (counterillumination function). Sharks use their luminescence mainly for this purpose. Specific lateral marks have been observed in Etmopteridae sharks (one of the two known luminous shark families) suggesting an inter/intraspecific recognition. Conversely, dorsal luminescence patterns are rare within these deepsea organisms.

Results: Here we report evidence that Etmopterus spinax, Etmopterus molleri and Etmopterus splendidus have dorsal luminescence patterns. These dorsal patterns consist of specific lines of luminous organs, called photophores, on the rostrum, dorsal area and at periphery of the spine. This dorsal light seems to be in contrast with the counterilluminating role of ventral photophores. However, skin photophores surrounding the defensive dorsal spines show a precise pattern supporting an aposematism function for this bioluminescence. Using in situ imaging, morphological and histological analysis, we reconstructed the dorsal light emission pattern on these species, with an emphasis on the photogenic skin associated with the spine. Analyses of video footage validated, for the first time, the defensive function of the dorsal spines. Finally, we did not find evidence that Etmopteridae possess venomous spine-associated glands, present in Squalidae and Heterondontidae, via MRI and CT scans.
\end{abstract}

Conclusion: This work highlights for the first time a species-specific luminous dorsal pattern in three deep-sea lanternsharks. We suggest an aposematic use of luminescence to reveal the presence of the dorsal spines. Despite the absence of venom apparatus, the defensive use of spines is documented for the first time in situ by video recordings.

Keywords: Etmopteridae, Dorsal pattern, Bioluminescence, Intraspecific recognition, Aposematism, Spines

\section{Background}

Deep in the ocean, a great many taxa have evolved the capability to emit light $[1,2]$. This phenomenon, called bioluminescence, is a mechanism whereby organisms emit visible light by biochemical reactions $[1,3,4]$. Functions of bioluminescence are mainly divided into three categories: predation, avoid predation (interspecific) and intraspecific communication [1,3-6]. Among these organisms, sharks are the first vertebrate to utilize this phenomenon $[1,7,8]$. Currently, there are two families of luminous deep-sea sharks (Etmopteridae and Dalatidae) which are capable of emitting a blue-green light (from 460 to $486 \mathrm{~nm}$ according to the species) thanks to thousands of tiny luminous

\footnotetext{
* Correspondence: Laurent.duchatelet@uclouvain.be

${ }^{1}$ Marine Biology Laboratory, Earth and Life Institute, Catholic University of

Louvain, Place Croix du Sud 3, 1348 Louvain-la-Neuve, Belgium

Full list of author information is available at the end of the article
}

organs, called photophores, mainly present on the ventral skin epidermis [7, 9-11]. The photophore structure, conserved in the genus Etmopterus, is composed of a "deep" pigmented sheet of embedded cells responsible for the light emission, called photocytes, surmounted by an iris-like structure topped externally by one or two lens cells [12-14]. Shark luminescence has been suggested to have several ecological roles. Firstly, like a large number of mesopelagic organisms emitting a continuous ventral glow similar to the down-welling light, lanternsharks use their ventral light to disrupt their silhouette and avoid being seen by predators swimming below; this is the counterillumination mechanism $[1,6,10,15]$. Secondly, interspecific and intraspecific communication have been suggested: (i) the presence of species-specific lateral flank marks may provide a way to facilitate reproductive isolation hence the high species richness in Etmopterus genus [8, 16], while (ii)

(c) The Author(s). 2019 Open Access This article is distributed under the terms of the Creative Commons Attribution 4.0 International License (http://creativecommons.org/licenses/by/4.0/), which permits unrestricted use, distribution, and 
sexual dimorphism is observed in the Etmopteridae species [12]. Aposematism is also suggested, provided by the spine associated photophore luminescence [17].

Previous studies have demonstrated that shark spines fulfill numerous functions, these include improving hydrodynamics of the organism and serving as a mechanism for defense. The presence of venomous glands associated with the posterior side of the spine in Heterodontidae and Squalidae are evidence for this function [18-22]. However, there is now in situ evidence for a defensive function of the dorsal spine in Etmopteridae. In contrast to ventral luminescence, dorsal luminescence is rare in the ocean and has received less interest, probably because it is easily detectable in contrast to the darker background from the deeper waters underneath the organism. This dorsal pattern is usually utilized for predation $[1,5]$, as indicated by the dorsal lure located above the jaws in anglerfish species [23] or for an anti-predatory function, where the light acts as an aposematic warning signal [24-26].

In this study, we investigated dorsal light emission in three deep-sea shark species from the Etmopteridae family: the velvet belly lanternshark, Etmopterus spinax (Linnaeus, 1758); the slendertail lanternshark, Etmopterus molleri (Whitley, 1939); and the splendid shark, Etmopterus splendidus (Yano, 1988). These three species are small deep-sea sharks (see Table 1) occurring at depths ranging from 200 to $500 \mathrm{~m}$, where sunlight dimly penetrates the water column [27-29]. Due to their small sizes, these sharks are preyed upon by larger organisms, such as other elasmobranch species including Dalatias licha, Echinorhinus cookei and large Hexanchiformes species ([30-33], JM personal communication). Lanternsharks are characterized by mineralized spines in front of dorsal fins, a subterminal notch on the dorsal part of the caudal fin and a specific pattern of light organs on the ventral and lateral body surface [11-13, 17]. A recent study highlighted the specialization of the visual system in luminous deep sea sharks compared to non-luminous species: (i) longer rod outer segments, higher rod densities and larger eye:body size ratio, these are in favor of high light sensitivity; (ii) maximal absorption wavelengths in visual pigments $(484-491 \mathrm{~nm})$ for perception of bioluminescent emissions $(476 \mathrm{~nm} E$. splendidus, $486 \mathrm{~nm}$ E. spinax and $488 \mathrm{~nm}$ E. molleri) and downwelling light; (iii) the presence of a secondary dorsal arch with a high density of rods in the retina which facilitates the detection of moving objects in the inferior visual field [34].

Our results reveal the presence of a dim blue-green light from the dorsal epidermis for these sharks. We report a species-specific dorsal pattern of photophores that may be utilized for species recognition, schooling, and other intraspecific communication. We also provide details of the specific luminous pattern associated with the spine in different Etmopteridae species. In this study, the first evidence of dorsal spine in a defensive use, is recorded by in situ video footages of Etmopteridae sharks. While CT and MRI scan images indicate that Etmopteridae sharks do not show the presence of a venomous gland associated with their spines.

\section{Materials and methods}

\section{Etmopteridae sampling}

The three elasmobranch species come from two different regions. E. spinax, is mainly found in the north-east part of the Atlantic, and were collected in the Raunefjord $\left(60^{\circ} 15^{\prime}\right.$ $54^{\prime \prime} \mathrm{N} ; 05^{\circ} 07^{\prime} 46^{\prime \prime}$ E) next to Bergen in Norway during winter 2017. A total of 31 specimens were sampled during this field session. They were caught using a deep-long line at a depth ranging from 180 to $250 \mathrm{~m}$. Specimens were transferred in a dark cold tank $\left(4^{\circ} \mathrm{C}\right)$ and brought to the Espegrend marine field station where they are kept alive in a seawater tank placed in a cold dark room $\left(4^{\circ} \mathrm{C}\right)$ until manipulations.

E. molleri and E. splendidus were collected in the East China Sea $\left(26^{\circ} 28^{\prime} 94^{\prime \prime} \mathrm{N} ; 127^{\circ} 41^{\prime} 20^{\prime \prime}\right.$ E) near the coast of Okinawa Island (Japan). They were fished using a bottom hook-and-line method at a depth ranging from 480 to $510 \mathrm{~m}$. Data on E. splendidus and E. molleri were collected during the fishing seasons winter 2011 and winter 2016, respectively. Three specimens of E. splendidus and 24 specimens of $E$. molleri were collected. All specimens were transferred to oxygen saturated plastic bags filled with seawater and transferred in a refrigerated box to the Okinawa Churaumi Aquarium where they were kept alive in a cold dark tank filled with seawater $\left(13^{\circ} \mathrm{C}\right)$ until manipulations.

Data on the collected specimens are summarized in Table 1.

Table 1 Mean morphological values. N: number of specimens; $ᄋ$ : female; $\widehat{\jmath}$ : male

\begin{tabular}{llllll}
\hline Species & $\mathrm{N}$ & Total length $(\mathrm{cm})$ & Fork length $(\mathrm{cm})$ & Pre-caudal length $(\mathrm{cm})$ & Weight $(\mathrm{g})$ \\
\hline Etmopterus spinax & $25 q$ & $46.3 \pm 1.1$ & $39.6 \pm 1.1$ & $35.6 \pm 1.1$ & $416.1 \pm 23.8$ \\
Etmopterus molleri & $6 \hat{\sigma}$ & $40.0 \pm 1.3$ & $35.2 \pm 1.3$ & $31.3 \pm 1.3$ & $248.1 \pm 34.2$ \\
& $15 q$ & $42.7 \pm 2.1$ & $36.7 \pm 1.9$ & $33.9 \pm 1.4$ & $217.6 \pm 43.1$ \\
Etmopterus splendidus & $9 \hat{\sigma}$ & $40.1 \pm 0.9$ & $33.8 \pm 0.9$ & $31.6 \pm 0.7$ & $165.6 \pm 17.2$ \\
\hline
\end{tabular}


Dorsal luminescence pattern analysis

Dorsal photos of luminous and living shark were taken with a Sony alpha 7S II camera (Sony Corporation, Japan), these images were analyzed, digital noise was removed using Photoshop software (Adobe; San Jose, CA, USA). Close-up images of the photogenic structure associated with the dorsal spines was also completed with the same software.

\section{Spine-associated luminous structure analysis}

Since photophores located on the dorsal fin (SAP) highlighting the spine were documented in E. spinax, we analyzed the structure and orientation of photophores located around the spines in different Etmopteridae species with the aim to compare arrangements among species.

Captive sharks were euthanized by a knock on the chondrocranium followed by an incision at the level of the spinal cord. The local rules for experimental fish care and the European regulation for research animal handling were followed. Shark dorsal skin, spine and fin were dissected and directly stored in $4 \%$ paraformaldehyde phosphate buffer saline (PBS) for $12 \mathrm{~h}$ at $4{ }^{\circ} \mathrm{C}$, and stored in PBS until further use. A $1.5 \mathrm{~cm}$ diameter skin patch around the spine was removed and separated from the spine. For histological analyses, dorsal skin, fin epidermis and skin patches were bath in PBS with increasing sucrose concentrations (10\% for $1 \mathrm{~h}, 20 \%$ for $1 \mathrm{~h}$ and finally, overnight in $30 \%$ sucrose), embedded in O.C.T. compound (Tissue-Tek, The Netherlands) and finally, rapidly frozen at $-80^{\circ} \mathrm{C}$. Thin sections $(10 \mu \mathrm{m})$ were cut with CM3050 S. Leica cryostat microtome (Germany) and were laid on Superfrost-coated slides (Thermo Scientific, Waltham, MA, USA) and left overnight to dry. Slides were analyzed using an epifluorescence microscope and a light microscope (Leitz Diaplan, Germany) equipped with a Nikon Coolpix 950 camera (Nikon, Japan). General morphology of the photophore, distance and the inclination angle $(\alpha)$ measured in relation to the spine location were all described. The photophore inclination angle (light pathway) was evaluated by taking the difference between the perpendicular to the iris opening as the reference axis and the line passing through the central point of the largest lens. Photophore distance was measured from the center of the light organ to the base of the spine. These two measurements were taken on pictures via ImageJ software [35]. Statistical analyses were performed with $\mathrm{JMP}^{\star}$ software (JMP ${ }^{\oplus}$, Version 13. SAS Institute Inc., Cary, NC, 19892007.). The Gaussian distribution respected an ANOVA followed by a Tukey-test to reveal significant differences.

\section{Computed tomography and MRI analyses}

Knowing that spine associated venom glands were detected as soft tissue located at the posterior side of the spine [18-20, 22], magnetic resonance imaging (MRI) data of the E. spinax spine and the associated tissues were obtained thanks to a Bruker Biospec 11,7 T (Bruker BioSpin, Ettlingen, Germany) in order to visualized the presence/absence of a specific venomous structure. A bird-cage coil with an internal diameter of $40 \mathrm{~mm}$ was used in emission/reception mode. The run sequence was Flash type with the following parameters: TE: $3.2 \mathrm{~ms}$; TR: $320 \mathrm{~ms}$; FA: $25^{\circ}$; matrix size: $396 \times 396$; field of vision of $30 \times 30 \mathrm{~mm}^{2}$; ten non-continuous slides separated from $350 \mu \mathrm{m}$ (center to center); resolution: $76 \times 76 \times 250 \mu \mathrm{m}^{3}$; number of repetitions: 700 . Computed tomography (CT) data of $E$. spinax were acquired using a cone beam micro-CT scanner (NanoSPECT/CT, Bioscan inc., Washington D.C., USA) with the following characteristics: spatial resolution: $48 \mu \mathrm{m}$; X-ray tube voltage: $45 \mathrm{kVp}$; number of projections: 360 ; exposure time: $1000 \mathrm{~ms}$. The CT projections were reconstructed with a voxel size of $0.111 \times 0.111 \times 0.11 \mathrm{~mm}^{3}$ by ray-tracing based filtered back projection.

\section{Video footage}

During the field session in November 2016, video footage of $E$. molleri was collected at one location in the oriental China Sea $\left(26^{\circ} 34^{\prime} 94^{\prime \prime}\right.$ N; $127^{\circ} 45^{\prime} 20^{\prime \prime}$ E). Two deployments occurred at depths of 500 and $540 \mathrm{~m}$. Each video device was on the seabed during a period of $2 \mathrm{~h}$. The underwater video system was designed by ourselves. Video footage was taken by a GoPro Hero 4 (GoPro, Inc., San Mateo, CA, USA) placed in a special underwater case, benthic 2 (Group B Distribution Inc., Jensen Beach, FL, USA) and fixed on the metal frame. The bait consisted of $1 \mathrm{~kg}$ of cephalopod and mackerel in a metal cage fixed to the frame by a steel bar. Lighting was provided by LED light in a housing, GPH-1750 M (Group B Distribution Inc.) and provided us a clear view until four meters and did not appear to disturb shark behaviors. The depth was recording using the sonar system of the boat.

\section{Results}

\section{Dorsal luminescence pattern}

Analysis of different dorsal luminous pictures allowed us to build schematic drawings of the dorsal side of each species (Fig. 1). Analyses of these patterns for each species revealed some luminous arrangements common to all species and others species-specific patterns: (i) the three luminous longitudinal lines from the back of the head to the beginning of the caudal fin were common for the three species studied (Fig. 1a-f), even if the median line of $E$. splendidus was denser than median line of the two other species; (ii) a relatively brighter luminous mark located on the ventral side of the caudal fin dorsal lobe was observed; (iii) on the rostrum dorsal side, despite many different patterns, the photophore aggregation 


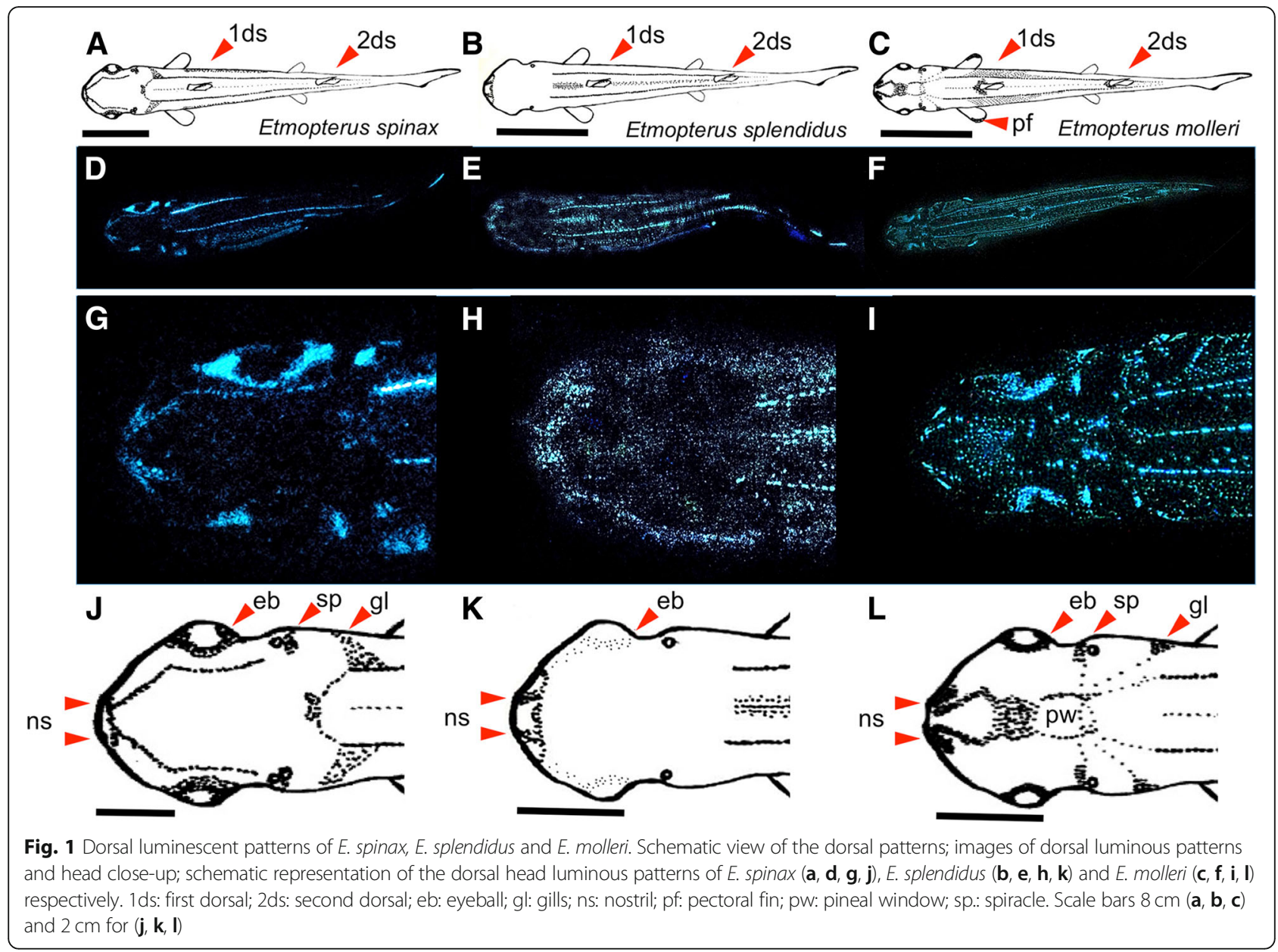

around nostrils was a common feature (Fig. 1g-l); (iv) a brighter luminous spot appeared next to the dorsal spines in these three species.

In addition to these similarities, many different luminous arrangements occurred between these three species, mainly focused on the rostrum and pectoral fins. Indeed, we saw that $E$. spinax and E. molleri show aggregation of the luminous organs around the eyes, next to spiracles and at the edge of gill slits. A luminous impala horn shape pattern was observed on the E. spinax head (Fig. 1g, j) and a particularly luminous shape arrangement was visible on $E$. molleri head (Fig. 1i, l). The pineal window surrounded by a circle of luminous dots from which radiating lines connecting spiracle, gills slits, and dorsal lines were visible. Between this window and the nostril, a luminous V shape and blotch were observed on the rostrum. Moreover, $E$. molleri shows a specific luminous zone on pectoral fins (Fig. 1c, f).

In contrast to these two species, E. splendidus possessed no specific luminous zones on the rostrum (Fig. 1h, k).

The dorsal light emission is about one order of magnitude dimmer than ventral light emission. We did not distinguish any sexual differences during our observations, although we observed that transferring the shark from a captivity tank to an aquarium induces a transient increase of bioluminescence lasting around $10 \mathrm{~min}$.

\section{Spine-associated luminous structure}

Close-up observations of the dorsal fin body region were performed to analyze spine-associated luminous structure for the three studied species (Fig. 2). Dissected spines with the $1.5 \mathrm{~cm}$ skin-associated allowed us to characterize two different spine-associated photogenic cluster patterns. Claes et al., (2013) describes the patterns in E. spinax, which consists of spine associated photophore, called SAP. These photophores are precisely localized along the fin anterior ridge facing the spine (Fig. 2a, d). This pattern was found and can be visualized through the thin dark strip on the antero-dorsal part of the fin (Fig. 2a, d). At this location, the photophores are oriented directly towards the spine and illuminate it (Fig. 2g). E. molleri did not show any photophores on the dorsal fin ridge (Fig. 2c, f, i) but careful examination of dorsal skin revealed the presence of luminous structures on the front and on each side of the spine base, 


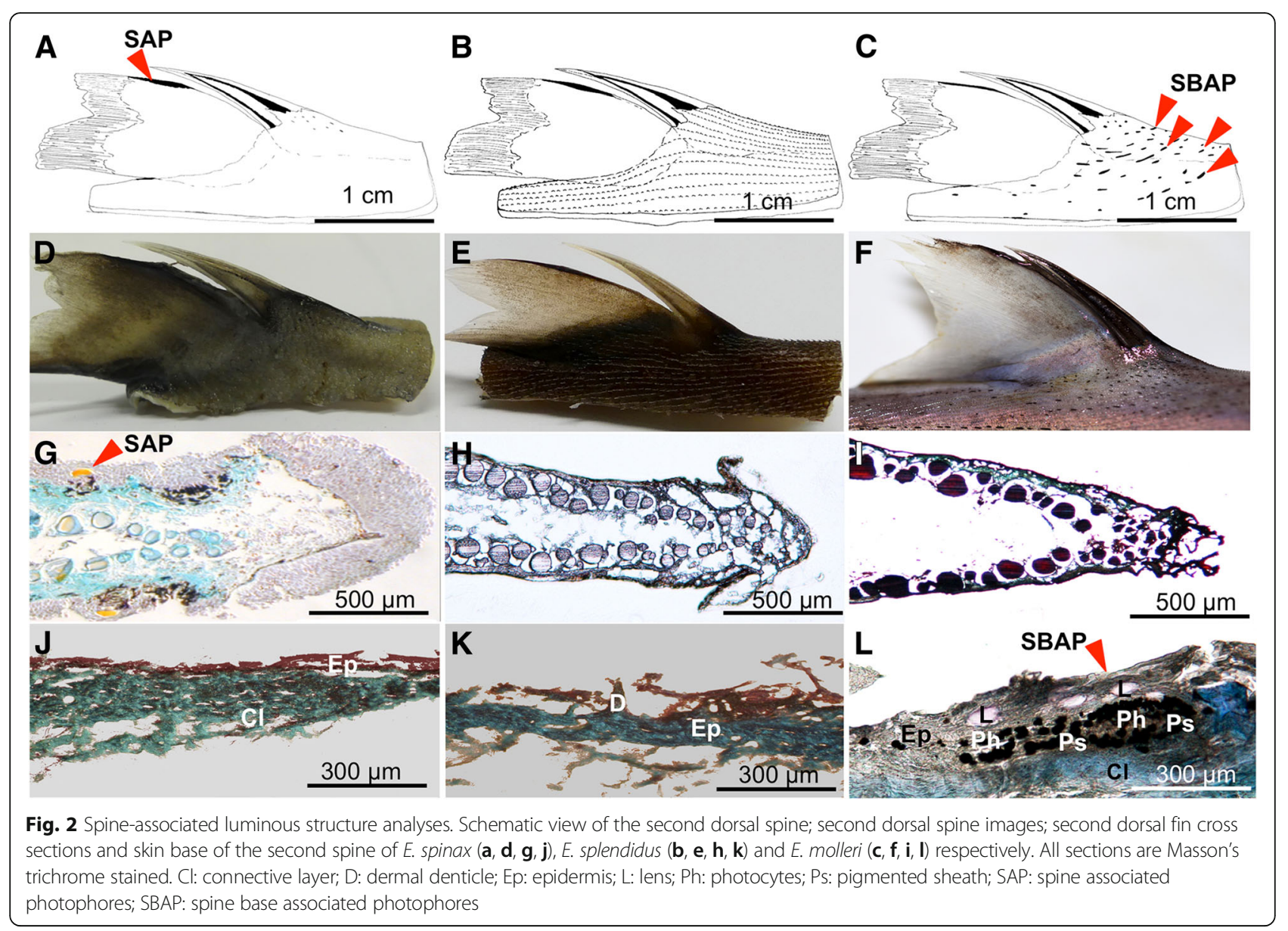

these photogenic structures were named spine base associated photophore (SBAP) (Fig. 2c, l). These photophores group together in small lines all around the spine with a rostro-caudal orientation (Fig. 2c, f). The size of SBAP clusters in front of the spine measured $775 \mu \mathrm{m} \pm$ 322 and side clusters were estimated as $443 \mu \mathrm{m} \pm 543$ (Fig. 3a). Longitudinal and transversal sections across SBAP allowed us to describe this new photophore type (Fig. 3b, e). SBAP is mainly composed of numerous photocytes forming an antero-posterior elongated tube shape, surrounded by pigmented cells and surmounted by at least five lens cells (Fig. 3a, b, e). These SBAPs are localized at a mean distance of $4.75 \pm 0.74 \mathrm{~mm}$ from the spine base ( $n=210$ SBAP observed). To find out if these photophore lines were able to illuminate the spines, the inclination angles $(\alpha)$ between the SBAP (Fig.3d, e) and ventral photophores (Fig. 3c, d) were measured. Ventral photophores showed an angle of $1.6^{\circ} \pm 0.8 \quad(n=42)$ significantly different from right side SBAP presenting a value of $29.1^{\circ} \pm 7.2(n=36)$ and left side, a value of $39.4^{\circ}$ $\pm 9.1(n=50)$ (Fig. 4; Tukey $p<.001)$. Regarding E. splendidus, no specific spine associated photophores (SAP/ SBAP) could be highlighted neither on the dorsal fin nor at the level of the spine base skin (Fig. 2b, e, h, k).
Spine structure and associated putative gland

To visualize a putative venom apparatus in Etmopteridae, MRI analysis was performed on fixed specimens; image analyses do not show any evidence of a soft tissue between the posterior side of the spine and the dorsal fin (Fig. 5a; Additional file 1). CT scan analyses did not allow to highlight any canal/duct on the anterior side of the spine that can be used for venom injection into a potential predator (Fig. 5b; Additional file 2).

\section{Video footage}

The video footage filmed in Okinawa allowed us to highlight the defensive function of the dorsal spine in Etmopteridae (Fig. 6). The video shows a sharpnose sevengill shark, Heptanchrias perlo (Bonnaterre, 1788), catching an Etmopterus splendidus (Fig. 6a), attempting to bite it twice (Fig. 6b, c, d), the shark then opened its jaws widely (Fig. 6e, f, g) letting the Etmopterus escape (Fig. 6h, i). The original recording is provided as Additional file 3.

We also observed sequences where a sevengill shark attempts to catch a lanternshark by the tail avoiding the spine sting, as shown on the Additional file 4. During field collections, caught lanternsharks were observed on 


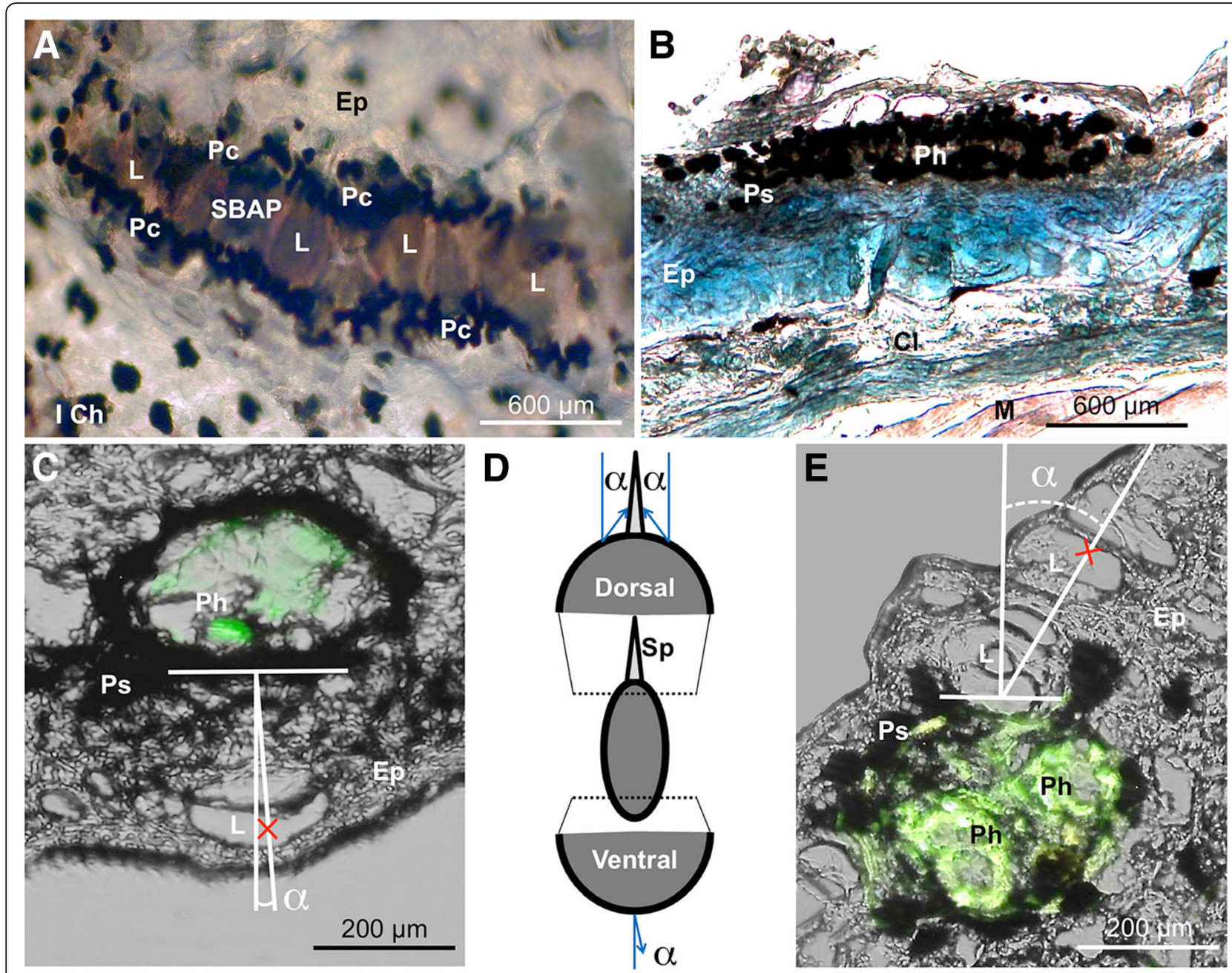

Fig. 3 Spine base associated photophore (SBAP) close up structure. a External view of SBAP showing lens cells and the pigmented crown. b Transversal section of SBAP showing the internal structure of this new photophore type. $\mathbf{c}$ Longitudinal section of ventral photophore with a mean inclination angle $<3^{\circ}$. d Schematic shark illustration showing ventral and SBAP inclination angles (e) Longitudinal section of SBAP with a mean inclination angle $\pm 35^{\circ}$ turned toward the spine. Red crosses correspond to the center of the biggest lens cell; $\mathrm{a}$ : angle; Ep: epidermis; I Ch: isolated chromatophore; Cl: connective layer; L: lens; M: muscle; Pc: pigmented crown; Ph: photocytes; Ps: pigmented sheath; Sp: spine

the hook with the tail cut off or the belly showing bite signs (Additional file 5).

\section{Discussion}

Among luminous organisms of the mesopelagic zone, dorsal luminescence is rare, as it seems counter-intuitive to produce a dorsal luminous signal making the emitter highly visible against the darkness of the deeper waters, while most organisms produce a ventral light to counterilluminate and escape from the sight of predators $[6$, 36-38]. We observed specific rostrum and dorsal light patterns, which may be utilized for intraspecific communication (schooling, mating), similarly to the dorsal caudal gland of certain Myctophidae fishes [39]. Assuming this intraspecific function, we suggest that this dorsal luminous pattern, like the specific flank marks of Etmopteridae, may have contributed to the large evolutionary radiation and speciation occurring in the Etmopterus genus [8, 16]. The dorsal lines already described in daylight by taxonomists were never referred as bioluminescent lines [40-42]. The species-specific patterns could be a useful feature for the Etmopteridae species determination/taxonomy, and therefore used as a new morphological phylogeny criterion.

However, Claes et al. (2013) have suggested the dorsal aposematic function of light for E. spinax, where the light from SAP (spine associated photophore) is strongly transmitted by the dorsal spine making it visible for potential predators. Our results show that handling the lanternshark species induces an increase of bioluminescence and the presence of a brighter spot of luminescence surrounding the spine areas, these findings agree with this aposematic function. However, in E. molleri we 


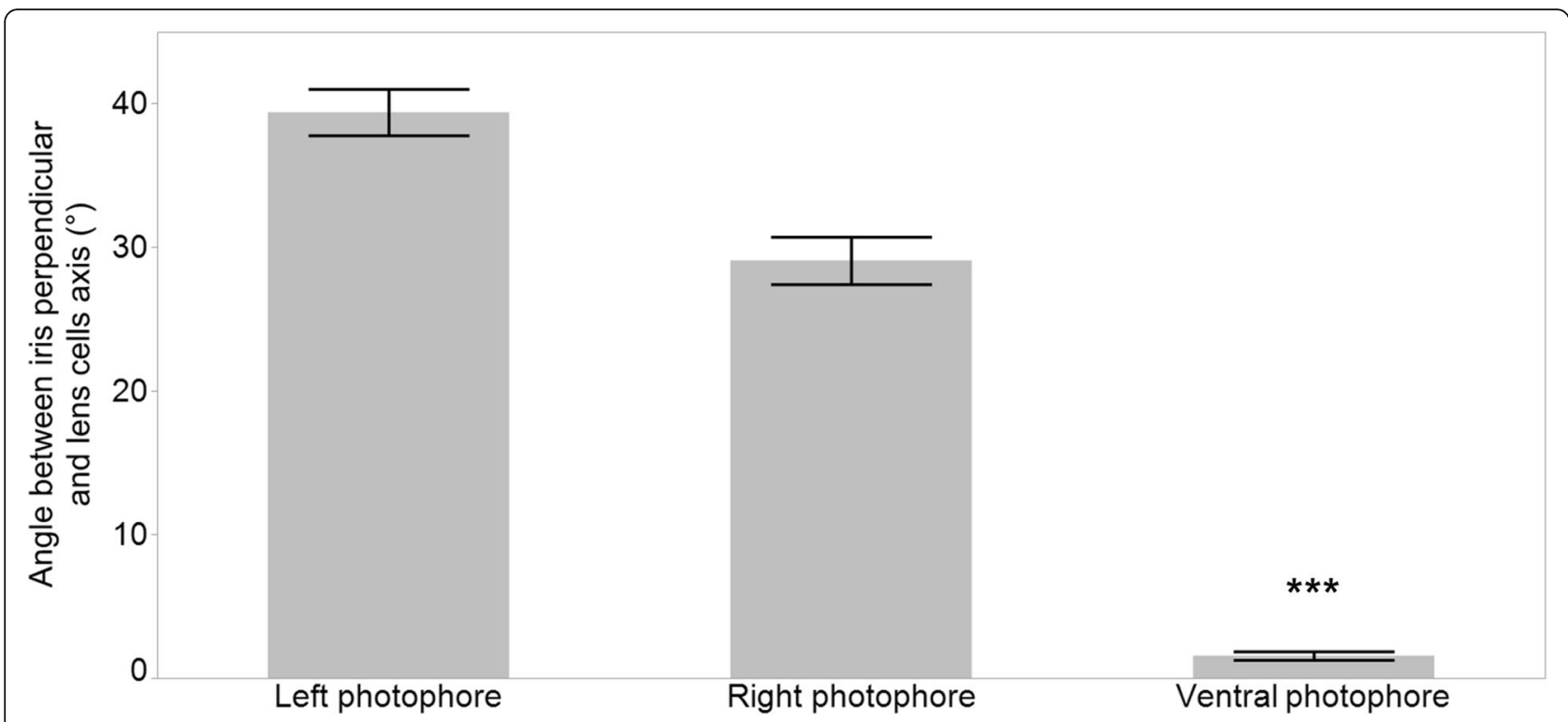

Fig. 4 Mean inclination angle between iris perpendicular and the lens cells axis of left and right spine base associated photophores (SBAPs) and ventral photophores

found a new elongated photophore type with numerous lenses whose orientation points towards the dorsal spine, we call these spine base associated photophore or SBAP. These are much larger than the photophore commonly described for Etmopteridae [7, 14, 43], and may represent a cluster of numerous photophores aiming to light up the spine. Consistent with the Squaliformes phylogeny, our results reveal a morphologically divergent evolution of photophore (SAP/SBAP) within Etmopteridae in order to reach a convergent functionality, aposematism. The primary homology hypothesis seems unlikely due to the positioning of the three studied species [44]. The use of conspicuous signals to warn predators of unprofitability, aposematism [45-48], has been suggested for bioluminescent organisms in terrestrial and oceanic environments [17, 24-26, 49-51].

The presence of a venomous gland at the spine base in two shark families (Squalidae and Heterodontidae) was considered proof of a defensive function of this spine $[18-20,22]$. Despite that no evidence of such gland was shown by MRI and CT scan analysis at the level of the dorsal spines in Etmopteridae, our video recordings and images are the first in situ validation of a defensive use of the dorsal spines. Attacks by predators at the level of

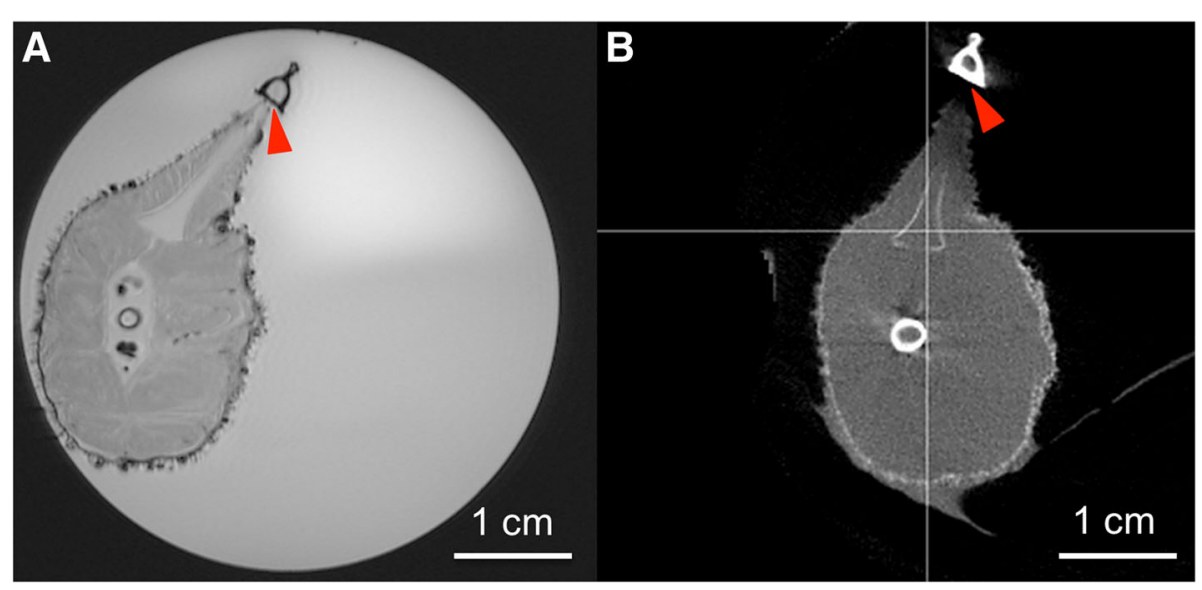

Fig. 5 Spine structure. Spine structure analyses by MRI image showing any evidence of soft tissue at the posterior side of the spine (red arrowhead) (a). Internal spine structure analyses by micro CT scan showing any evidence of a duct/canal at the posterior side of the spine hard tissue (calcified structure), red arrowhead showing the calcified tissue at the posterior side of the spine without any duct/canal (b). In both analyses, the only hollow on the spine, at the center, is filled with cartilaginous matrix 

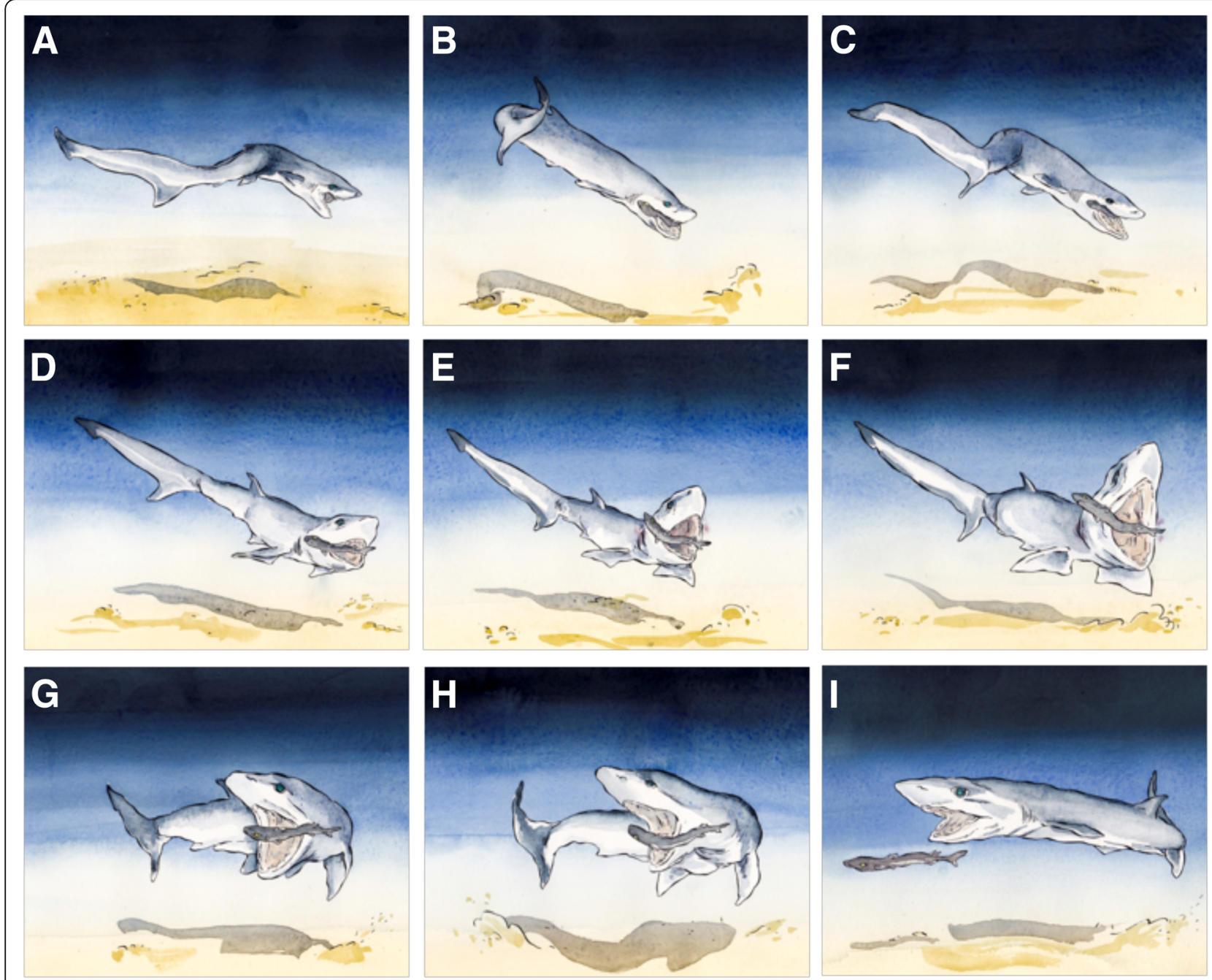

Fig. 6 Schematic time-lapse of hunting behavior of H. perlo on an E. splendidus where the spine defensive function is illustrated (images taken from video footage see supplemental materials)

the belly and tail of Etmopteridae seem to indicate that learning behavior has led predators to specifically avoid dorsal spines during predation attempts.

\section{Conclusion}

This work highlights for the first time a species-specific luminous dorsal pattern in three deep-sea lanternsharks. New photophore assemblages were described and their arrangement suggests an aposematic use of luminescence to reveal the presence of the dorsal spines. In Etmopteridae, a morphological divergence might be involved in a convergent function, aposematism. Despite the absence of venomous apparatus, the defensive use of spines is documented for the first time by in situ video recordings. Development of highly sensitive underwater video recording devices could allow footage of bioluminescence to be recorded, revealing the use of living light by deep-sea sharks during encounters with conspecifics or predators.

\section{Additional files}

Additional file 1: Animated GIF of MRI transversal section of Etmopterus spinax at the level of spine base, going from the tip to the base of the spine. (GIF $557 \mathrm{~kb}$ )

Additional file 2: Animated GIF of CT scan sagittal section of Etmopterus spinax dorsal spine and fin, starting from the body (1) till the end of the spine (4) and backward. (GIF $74 \mathrm{~kb}$ )

Additional file 3: Video recording of Heptanchrias perlo attack on an Etmopterus splendidus body. (MOV $6040 \mathrm{~kb}$ )

Additional file 4: Video recording of Heptanchrias perlo attack on an Etmopterus molleri tail. (MOV $2448 \mathrm{~kb}$ )

Additional file 5: Pictures of injured E. molleri collected by deep sea rod fishing (A) Tail cut; (B) ventral side open; (C) closer view of B; (D) another occurrence of ventral bite. Scale bar $A=3 \mathrm{~cm}, B-C-D=4 \mathrm{~cm}$. (TIF $19094 \mathrm{~kb}$ )

\section{Acknowledgements}

We would like to thank T. Sorlie from the Espegrend Marine Biological Station (University of Bergen, Norway) for the help during E. spinax collection, the husbandry staff from the Okinawa Churaumi Aquarium for the help provided during E. molleri and E. splendidus field sampling. We acknowledge the Louvain 
Drug Research Institute and the Institute of Neuroscience for the help they provide in MRI and CT scan analyses, respectively. Finally, we thank Muriel Blondeau for the time-lapse drawing provided. The authors want to acknowledge the anonymous reviewers whose comments improve the present manuscript.

\section{Funding}

This work was supported by a grant from the Fonds de la Recherche Scientifique (FRS-FNRS, Belgium) to L.D., N.P., JM.

\section{Availability of data and materials}

Please contact author for data requests.

\section{Authors' contributions}

L.D., N. P., T.T. and J.M. collected data, L.D., N. P. and J.M. contributed to data analysis and article preparation, T.T. and K.S. provided access to the field and revised the manuscript. All authors reviewed the final version and agree to final article submission.

\section{Authors' information}

L.D. and N.P. are PhD students under a FRIA fellowship; T.T. is under Researcher fellowship from Okinawa Churashima Foundation Research Center; K.S. is Deputy Director General of the Okinawa Churaumi Aquarium; and J.M. is Research Associate to FRS-FNRS. This paper is a contribution to the Biodiversity Research Center (BDIV) and the Center Interuniversitaire de Biologie Marine (CIBIM).

\section{Ethics approval and consent to participate}

Etmopterus spinax were collected in Norway under the "experimental fish care permit" number 12/14048. Etmopterus molleri and splendidus were collected and handled according to Churaumi aquarium husbandry and veterinary rules for fish experimentations. All sharks were euthanized by a knock on the chondrocranium followed by an incision at the level of the spinal cord, following the local rules for experimental fish care and the European regulation for research animal handling. These species are not in the CITES list.

\section{Consent for publication}

Not applicable.

\section{Competing interests}

The authors declare that they have no competing interests.

\section{Publisher's Note}

Springer Nature remains neutral with regard to jurisdictional claims in published maps and institutional affiliations

\section{Author details}

'Marine Biology Laboratory, Earth and Life Institute, Catholic University of Louvain, Place Croix du Sud 3, 1348 Louvain-la-Neuve, Belgium. ${ }^{2}$ Okinawa Churaumi Aquarium, 424 Ishikawa, Motobu-cho, Okinawa prefecture 905-0206, Japan. ${ }^{3}$ Zoological Laboratory, Okinawa Churashima Research Center, 888 Ishikawa, Motobu-cho, Okinawa 905-0206, Japan.

\section{Received: 17 July 2018 Accepted: 25 February 2019}

\section{Published online: 06 March 2019}

\section{References}

1. Haddock SDH, Moline MA, Case JF. Bioluminescence in the sea. Annu Rev Mar Sci. 2010;2:443-93. https://doi.org/10.1146/annurev-marine-120308-081028.

2. Martini S, Haddock SDH. Quantification of bioluminescence from the surface to the deep sea demonstrates its predominance as an ecological trait. Sci Rep. 2017;7:45750. https://doi.org/10.1038/srep45750.

3. Herring PJ. How to survive in the dark: bioluminescence in the deep-sea. Symp Soc Exp Biol. 1985;39:323-50.

4. Shimomura O. Bioluminescence: chemical principles and methods. Singapore: World Scientific Publishing Company; 2006.

5. Buck JB. Bioluminescence in action (ed. Herring, P.J.). New York: Academic Press; 1978.

6. Clarke WD. Function of bioluminescence in mesopelagic organisms. Nature. 1960;198:1244-6. https://doi.org/10.1038/1981244a0.
7. Claes JM, Nilsson DE, Straube N, Collin SP, Mallefet J. Iso-luminance counterillumination drove bioluminescent shark radiation. Sci Rep. 2014:4 4328. https://doi.org/10.1038/srep04328.

8. Straube N, Iglésias SP, Sellos DY, Kriwet J, Schliewen UK. Molecular phylogeny and node time estimation of bioluminescent lantern sharks (Elasmobranchii: Etmopteridae). Mol Phylogenet Evol. 2010;56(3):905-17. https://doi.org/10.1016/j.ympev.2010.04.042

9. Claes JM, Mallefet J. Early development of bioluminescence suggests camouflage by counter-illumination in the velvet belly lanternshark Etmopterus spinax (Squaloidea: Etmopteridae). J Fish Biol. 2008;73(6):133750. https://doi.org/10.1111/j.1095-8649.2008.02006.x.

10. Claes JM, Aksnes DL, Mallefet J. Phantom hunter of the fjords: camouflage by counterillumination in a shark (Etmopterus spinax). J Exp Mar Biol Ecol. 2010;388(1):28-32. https://doi.org/10.1016/j.jembe.2010.03.009.

11. Ebert DA, Fowler SL, Compagno LJ. Sharks of the world: a fully illustrated guide. Plymouth: Wild Nature Press; 2013

12. Claes JM, Mallefet J. Ontogeny of photophore pattern in the velvet belly lanternshark, Etmopterus spinax. Zoology. 2009;112(6):433-41. https://doi. org/10.1016/i.zool.2009.02.003.

13. Claes JM, Sato K, Mallefet J. Morphology and control of photogenic structures in a rare dwarf pelagic lanternshark (Etmopterus splendidus). J Exp Mar Biol Ecol. 2011;406(1):1-5. https://doi.org/10.1016/j.jembe.2011.05.033.

14. Renwart M, Delroisse J, Claes JM, Mallefet J. Ultrastructural organization of lanternshark (Etmopterus spinax Linnaeus, 1758) photophores. Zoomorphology. 2014;133(4):405-16. https://doi.org/10.1007/s00435-014-0230-y.

15. Young RE, Kampa EM, Maynard SD, Mencher FM, Roper CFE. Counterillumination and the upper depth limit of midwater animals. Deepsea Res A. 1980;27:671-91. https://doi.org/10.1016/0198-0149(80)90022-9.

16. Claes JM, Nilsson DE, Mallefet J, Straube N. The presence of lateral photophores correlates with increased speciation in deep-sea bioluminescent sharks. Royal Soc Open Sci. 2015;2(7):150219. https://doi.org/ 10.1098/rsos.150219.

17. Claes JM, Dean MN, Nilsson DE, Hart NS, Mallefet J. A Deepwater fish with 'lightsabers'-dorsal spine-associated luminescence in a counterilluminating lanternshark. Sci Rep. 2013;3:1308. https://doi.org/10.1038/srep01308.

18. Haddad JV, Gadig OBF. The spiny dogfish ('cação-Bagre'): description of an envenoming in a fisherman, with taxonomic and toxinologic comments on the Squalus gender. Toxicon. 2005:46(1):108-10. https://doi.org/10.1016/j. toxicon.2005.03.002

19. Haddad JV, Lima C, Lopes-Ferreira M. Venomous Marine Fish: Evolution of the Venoms-Chondrichthyes (Cartilaginous Fish). Mar Freshwat Toxins: Mar Freshwat Toxins. 2014:1-5. https://doi.org/10.1007/978-94-007-6650-1_9-1.

20. Halstead BW, Bunker NC. The venom apparatus of the ratfish, Hydrolagus colliei. Copeia. 1952;3:128-38. https://doi.org/10.2307/1439692.

21. Lauder GV, Drucker EG. Morphology and experimental hydrodynamics of fish fin control surfaces. IEEE J Ocean Eng. 2004;29(3):556-71. https://doi. org/10.1109/JOE.2004.833219.

22. Maisey JG. Finspine morphogenesis in squalid and heterodontid sharks. Zool J Linnean Soc. 1979:66:161-83. https://doi.org/10.1111/j.1096-3642. 1979.tb01907.x.

23. Widder EA. Bioluminescence in the ocean: origins of biological, chemical, and ecological diversity. Science. 2010;328(5979):704-8. https://doi.org/10. 1126/science.1174269.

24. Deheyn DD, Wilson NG. Bioluminescent signals spatially amplified by wavelength-specific diffusion through the shell of a marine snail. Proc $\mathrm{R}$ Soc Lond B Biol Sci. 2010; rspb20102203. https://doi.org/10.1098/rspb.2010.2203.

25. Grober MS. Brittle-star bioluminescence functions as an aposematic signal to deter crustacean predators. Anim Behave. 1988;36(2):493-501. https://doi. org/10.1016/S0003-3472(88)80020-4.

26. Herring PJ, Widder EA. Bioluminescence of deep-sea coronate medusae (Cnidaria: Scyphozoa). Mar Biol. 2004;146(1):39-51. https://doi.org/10.1007/ s00227-004-1430-7.

27. Clarke $G L$, Backus RH. Measurements of light penetration in relation to vertical migration and records of luminescence of deep-sea animals. Deep Sea Res. 1957;4:1-14. https://doi.org/10.1016/0146-6313(56)90026-0.

28. Duntley SQ. Light in the sea. JOSA. 1963;53(2):214-33. https://doi.org/10. 1364/JOSA.53.000214.

29. Aksnes DL, Røstad A, Kaartvedt S, Martinez U, Duarte CM, Irigoien X Light penetration structures the deep acoustic scattering layers in the global ocean. Sci Adv. 2017;3(5):e1602468. https://doi.org/10.1126/ sciadv. 1602468 
30. Clarke MR, Merret N. The significance of squid, whale and other remains from the stomachs of bottom-living deep-sea fish. J Mar Biol Assoc U K. 1972;52(3):599. https://doi.org/10.1017/S0025315400021603.

31. Matallanas J. Feeding habits of Scymnorhinus licha in Catalan waters. J Fish Biol. 1982;20:155-63. https://doi.org/10.1111/j.1095-8649.1982.tb03916.x.

32. Santos J, Borges T. Trophic relationships in deep-water fish communities off Algarve, Portugal. Fish Res. 2001;51(23):337-41. https://doi.org/10.1016/ S0165-7836(01)00257-0.

33. Navarro J, López L, Coll M, Barría C, Sáez-Liante R. Short- and long-term importance of small sharks in the diet of the rare deep-sea shark Dalatias licha. Mar Biol. 2014;161:1697-707. https://doi.org/10.1007/ s00227-014-2454-2.

34. Claes JM, Partridge JC, Hart NS, Garza-Gisholt E, Ho H-C, Mallefet J, Collin SP. Photon hunting in the twilight zone: visual features of mesopelagic bioluminescent sharks. PLoS One. 2014;9(8):e104213. https://doi.org/10.1371/ journal.pone.0104213.

35. Schindelin J, Rueden CT, Hiner MC, Eliceiri KW. The imageJ ecosystem: an open plateform for biomedical image analysis. Mol Reprod Dev. 2015;82(78):518-29. https://doi.org/10.1002/mrd.22489.

36. Catul V, Gauns M, Karuppasamy PK. A review on mesopelagic fishes belonging to family Myctophidae. Rev Fish Biol Fisher. 2011;21(3):339-54. https://doi.org/10.1007/s11160-010-9176-4.

37. Jones BW, Nishiguchi MK. Counterillumination in the hawaiian bobtail squid, Euprymna scolopes berry (Mollusca: Cephalopoda). Mar Biol. 2004;144(6): 1151-5. https://doi.org/10.1007/s00227-003-1285-3.

38. Latz MI. Physiological mechanisms in the control of bioluminescent countershading in a midwater shrimp. Mar Freshw Behav Physiol. 1995; 26(2-4):207-18. https://doi.org/10.1080/10236249509378940.

39. Herring PJ. Sex with the lights on? A review of bioluminescent sexual dimorphism in the sea. J Mar Biol Assoc UK. 2007;87(4):829-42.

40. Ebert DA, Compagno LJV, De Vries MJ. A new Lanternshark (Squaliformes: Etmopteridae: Etmopterus) from southern Africa. Copeia. 2011;2011(3):37984. https://doi.org/10.1643/Cl-09-183.

41. Vasquez VE, Ebert DA, Long DJ. Etmopterus benchleyi n. Sp., a new lanternshark (Squaliformes: Etmopteridae) from the central eastern Pacific Ocean. J Ocean Sci Found. 2015;17:43-55.

42. White WT, Ebert DA, Mana RR, Corrigan S. Etmopterus samadiae n. Sp., a new lanternshark (Squaliformes: Etmopteridae) from Papua New Guinea. Zootaxa. 2017:4244(3):339-54. https://doi.org/10.11646/zootaxa.4244.3.3.

43. Claes JM, Mallefet J. Bioluminescence of sharks: first synthesis. Bioluminescence in Focus-A Collection of Illuminating Essays. Kerala: Research Signpost; 2009. p. 51-65.

44. Straube N, Li C, Claes JM, Corrigan S, Naylor GJP. Molecular phylogeny of Squaliformes and first occurrence of bioluminescence in sharks. BMC Evol Biol. 2015;15:162. https://doi.org/10.1186/s12862-015-0446-6.

45. Cott HB. Adaptive coloration in animals. London: Menthuen \& Co; 1940

46. Lindstrom L. Evolution of conspicuous warning signals (PhD dissertation). Jyväskylä: University of Jyväskylä; 2000

47. Poulton EB. The colours of animals: their meaning and use. Especially considered in the case of insects. London: Kegan Paul, Trench, Trübner \& Co; 1890

48. Yachi S, Higashi M. The evolution of warning signals. Nature. 1998;394(6696): 882. https://doi.org/10.1038/29751.

49. De Cock R, Matthysen E. Aposematism and bioluminescence: experimental evidence from glow-worm larvae (Coleoptera: Lampyridae). Evol Ecol. 1999; 13(7-8):619-39. https://doi.org/10.1023/A:1011090017949.

50. De Cock R, Matthysen E. Glow-worm larvae bioluminescence (Coleoptera: Lampyridae) operates as an aposematic signal upon toads (Bufo bufo) Behav Ecol. 2003;14(1):103-8. https://doi.org/10.1093/beheco/14.1.103.

51. Marek P, Papaj D, Yeager J, Molina S, Moore W. Bioluminescent aposematism in millipedes. Curr Biol. 2011;21(18):R680-1. https://doi.org/10. 1016/j.cub.2011.08.012.

Ready to submit your research? Choose BMC and benefit from:

- fast, convenient online submission

- thorough peer review by experienced researchers in your field

- rapid publication on acceptance

- support for research data, including large and complex data types

- gold Open Access which fosters wider collaboration and increased citations

- maximum visibility for your research: over $100 \mathrm{M}$ website views per year

At $\mathrm{BMC}$, research is always in progress.

Learn more biomedcentral.com/submissions 